\title{
NURSE RESILIENCE IN ACUTE CLINICAL SETTINGS
}

\author{
Kaitlin Perry
}

\section{INTRODUCTION}

Nurses practising in New Zealand (NZ) face difficult, ever-changing and dynamic challenges in the workplace (New Zealand Nurses Organisation [NZNO], 2020). These include an increasing population, an ageing nursing workforce, local and global health care environments that are in a state of continuous change, a tightening economic climate and unpredictability in the nursing workforce (NZNO, 2020). In these times, a lack of nurse resilience can result in burnout, moral distress and high job turnover. Nurse burnout can result in detrimental health outcomes, such as drug and alcohol abuse and psychological distress (Vahey, Aiken, Sloane, Clarke, \& Vargas, 2004). These negative effects highlight the importance of developing resilience as a nurse, in order to achieve improved health outcomes for all.

In this paper, I focus on five major themes which appear repeatedly throughout the literature. While existing literature regarding the creation of resilience represents these themes in a variety of contexts, the content of this paper will primarily focus on their application to nurse resilience in the acute clinical setting.

\section{CLINICAL ISSUE}

Resilience is a strategy for overcoming challenges in the nursing profession (Yilmaz, 2017). Lowe (2013) suggests that nurses who adopt resilient characteristics reduce the incidence of stress and burnout while increasing the quality of patient care and inspiring better health outcomes. Aburn, Gott, and Hoare (2016) define resilience as the ability of a person to effectively cope or bounce back despite adverse conditions. Furthermore, Connor (2006) suggests that resilience alleviates moral distress and burnout throughout the nursing profession. Complementary to this, Epstein, Burns, and Conlon (2010) indicate that increased stress levels can cause negative effects such as burnout, moral distress, mental health issues and substance abuse as nurses in the acute clinical setting make an effort to practise in such a way that aligns with their personal and professional values.

A recent clinical placement in an acute setting heightened my awareness of how practising as a nurse is not only emotionally draining, but physically demanding as well. Resilience is an extremely relevant issue in nursing, and it enables a sustainable nursing profession. Observing burnout and high stress levels among nurses, and the impact this has on the level of care patients receive, made me think about what makes a nurse resilient and the important role resilience plays in nursing care. So, how can nurse resilience be enhanced in the acute clinical setting? 


\section{BACKGROUND}

Woods, Rodgers, Towers, and La Grow (2014) conducted a national New Zealand survey and found that moral distress is highly prevalent in NZ nurses. This can be a result of having to deliver less than optimal care due to decisions made by management, which can cause patients to suffer in terms of their care. Woods et al. (2014) also concluded that other factors which can create moral distress are working with nurses who are not competent and witnessing reduced quality of care due to poor communication within the nursing workforce. The World Health Organisation (WHO) reinforce this view by noting that, currently, there is an increased demand and a decreased supply of nurses; it is predicted there will be a global issue of clinical staff shortages with a predicted shortage of 2.4 million health care professionals, with nurses being the largest proportion of the deficit (WHO, 2006).

\section{Evidence and Findings}

Resilience assists individuals to lessen burnout and moral distress (Rushton et al., 2015). Various intervention studies (Rushton et al., 2015; Tabakakis et al., 2019; Yilmaz, 2017) show strategies that build resilience. The following five themes were common to the literature around ways of developing resilience in nurses in the clinical setting: self-efficacy, coping mechanisms, mindfulness, support, and optimism.

\section{Self-efficacy}

Rushton et al. (2015) emphasise that resilience can be improved through self-efficacy. A common definition of selfefficacy is a person's belief in their own ability to perform a particular task (Garcia-Dia et al., 20I3). In the context of nursing, Gillespie, Chaboyer, and Wallis (2007) inform the reader that self-efficacy is confidence in knowledge as well as decision-making in everyday practice. To produce a stable workforce in New Zealand with nurses who remain in the job and have the self-efficacy to handle significant stress, resilience training should be implemented as a component in the education of nurses.

\section{Coping mechanisms}

McAllister and McKinnon (2009) suggest that coping mechanisms increase resilience and regulate emotions, therefore reducing burnout and its consequences. Coping mechanisms can be viewed as protective factors that are necessary for surviving stressful or traumatic experiences, as they assist people to withstand challenges and grow from them (McAllister \& McKinnon, 2009). Lim, Bogossian, and Ahern (2010) identified a variety of coping strategies including problem solving, seeking social support, self-controlling, escape-avoidance and distancing. Coping skills are able to be learned and strengthened through educational experiences. A range of coping skills that can be put into practice during challenging times, enables a more resilient individual (McAllister \& McKinnon, 2009). This idea is supported by Lowe (2013), who expressed the opinion that improved well-being and positive coping skills are shown to be effective in reducing stress levels and fostering characteristics of resilience. Kornhaber and Wilson (20 II), along with Glass and Rose (2008), hypothesised that formal supports, for instance professional counselling and clinical supervision, have shown to be successful coping strategies and ways of managing workplace adversity, additionally contributing to mental health and wellbeing.

\section{Mindfulness}

Badu et al. (2020) identified that mindfulness is particularly important to all nurses. Through mindfulness, the nurse is in a position to separate themselves from highly stimulating emotional circumstances, as it allows them to reflect, learn and move on. Mindfulness can be viewed as a necessary construct when building and maintaining resilience (Cusack et al., 2016). It is a characteristic that involves focusing completely on an experience in an understanding or non-judgemental way. Based on the ideas of Grafton, Gillespie, and Henderson (20I0), developing a workforce that is strong and resilient can be directly linked to the improvement of mindfulness. 


\section{Support}

As explained by Lowe (2013), a supportive and healthy work environment for nurses will foster resilience and reduce the impact of stress. Supportive social networks contribute to the regulation of the effects of challenging work environments and have been proven to be features of resilient nurses. Van Heugten (2012) explains how collaborating with colleagues and building strong relationships have been shown to reduce risk factors associated with demanding situations, such as the risk for depression, anxiety and post-traumatic stress disorder. Workplaces where nurses are inspired to develop trust, faith and hope with one another, assist with cultivating caring relationships. Hart, Brannan, and De Chesnay (2012) concluded that human interaction and deep connections with other individuals were important factors that contributed to an individual's development of resilience.

\section{Optimism}

As outlined by Hart et al. (2012), optimism and a hopeful outlook are widespread characteristics of resilient nurses. Nurses who have the ability to look forward to a future time when the current situation may be altered, were correlated with increased resilience (Hart et al., 2012). A cross-sectional survey conducted by Rushton et al. (2015) found that nurses recognised influences such as spirituality and optimism as ways to cope with stressful work environments. Similar to optimism, hope was also found to be a key influence of resilience, and nurses who felt a sense of hope were able to gain meaning and felt as though they had purpose in life (Rushton et al., 2015). The results from this study organised by Rushton et al. (2015) also suggested that hope fuels work satisfaction, and nurses who had higher levels of hope scored higher on personal achievement. Given that hope is able to decrease moral distress, enhance resilience and avoid burnout, then fostering a nurse's capacity for hope may be the solution to the harmful effects of moral distress.

\section{RECOMMENDATIONS}

The following three recommendations have been developed in an attempt to enhance nurse resilience in the acute clinical setting:

Recommendation One: incorporate resilience education within undergraduate health professional programmes. Resilience is a concept that has been somewhat ignored in the education of health professionals such as nurses. Resilience has been shown to directly relate to the wellbeing of an individual (McAllister \& McKinnon, 2009). The five themes discussed above are all intrapersonal qualities that are able to be learned and expanded on through education. Developing their character, students should be able to explore their own values and beliefs in order to understand their professional identity. Students of health professional programmes should focus on coping and strength development where they articulate and are able to answer questions around how to be prepared for the workforce, and how to succeed and cope in unknown situations. Students will become future leaders; therefore, they need to learn how to be leaders for change and cope with work challenges acting in a respectful, engaging, and collaborative way (McAllister \& McKinnon, 2009).

Recommendation Two: allow opportunities for workers to reflect upon and learn from experiences in practice, with other health professionals. Using strategies such as debriefing, self-reflection and validation can improve the resilience of nurses. Initiatives such as professional skills development, professional attributes and supportive workplace environments also build resilience (Cusack et al., 2016; Yilmaz, 2017). Exposure to positive role models who can enlighten other staff members on how to thrive in acute healthcare settings would be an important and valuable teaching and learning opportunity (McAllister \& McKinnon, 2009). Clinicians who demonstrate resilience and post-traumatic growth have the potential to be inspiring role models. Therefore, there are benefits in communicating insights from adversity not only with students and new graduates, but also with lifelong learners (McAllister \& McKinnon, 2009). Interventions such as clinical supervision allow individuals to share personal nursing experience and understand how to cope with difficulties in the nursing workplace, 
as well as recognising and being educated on the different strategies, such as expression, talking and problem solving (McAllister \& McKinnon, 2009). Other initiatives such as professional counselling, an employee assistance programme or clinical supervision are effective methods for managing workplace adversity (Badu et al., 2020).

Recommendation Three: staff should be provided with environmental support which includes facilities such as a quiet room where staff have the opportunity to wind down, debrief, or pray. This would enable nurses in these settings to participate in self-care activities within the acute setting, encouraging them to develop and strengthen personal and professional resilience (Grafton et al., 20I0). This would also provide an opportunity for further reflection, enabling the nurse to advance in their journey of resilience (Best, 2019). As emphasised by Best (2019), being able to manage one's own personal health and well-being is just as important as caring for the patient.

\section{CONCLUSION}

In this paper I have provided an up-to-date overview of the concept of resilience for nurses working within the acute clinical setting. Working in stressful environments with high patient acuity, registered nurses are prone to burnout, moral distress and emotional exhaustion. Awareness of factors that build resilience, such as the five themes which emerged from the literature, mitigates the detrimental effects of the current health care environment, thus developing a strong nursing workforce. Incorporation of further education for nursing students and nurses in the workforce about the importance of resilience and developing their own approaches within the five strategies to enhance resilience, in the context of current challenges in the New Zealand nursing workforce, should help to combat the nursing shortage by strengthening those currently employed.

Kaitlin Perry is a third-year Nursing student at Otago Polytechnic. This paper was the result of an exploration of ways to keep nurses in the profession by building resilience. She has a passion for caring for others and loves how dynamic and rewarding the nursing profession is.

Correspondence to: Kaitlin Perry, School of Nursing, Otago Polytechnic | Te Kura Matatini ki Otago, Forth Street, Private Bag 1910, Dunedin 9054, New Zealand. Email: kaitlinperryl0@gmail.com

\section{REFERENCES}

Aburn, G., Gott, M., \& Hoare, K. (2016). What is resilience? An Integrative review of the empirical literature. Journal of Advanced Nursing, 72(5), 980-1000. https://doi.org/l0.1111/jan.12888

Badu, E., O'Brien, A., Mitchell, R., Rubin, M., James, C., McNeil, K., ... Nguyen, K. (2020). Workplace stress and resilience in the Australian nursing workforce: A comprehensive integrative review. International Journal of Mental Health Nursing, 29(I), 5-34. https://doi.org//0.1111/inm. 12662

Best, C. (2019). Building resilience in contemporary nursing practice. Practice Nursing, 30(8), 400-404. https://doi.org/l0.12968/ pnur.2019.30.8.400

Connor, K. (2006). Assessment of resilience in the aftermath of trauma. Journal of Clinical Psychiatry, 67(2), 46-49. Retrieved from https://www.psychiatrist.com/jcp/article/pages/2006/v67s02/v67s0207.aspx

Cusack, L., Smith, M., Hegney, D., Rees, C., Breen, L., Witt, R., ... Rogers, C. (2016). Exploring environmental factors in nursing workplaces that promote psychological resilience: Constructing a unified theoretical model. Frontiers in Psychology, 7(600), 2-6. https://doi.org/10.3389/fpsyg.2016.00600 
Epstein, P., Burns, C., \& Conlon, H. (20I0). Substance abuse among registered nurses. AAOHN Journal, 58(I2), 513-516. https:// doi.org/l0.1177/216507991005801203

Garcia-Dia, M., DiNapoli, J., Garcia-Ona, L., Jakubowski, R., \& O'Flaherty, D. (2013). Concept analysis: Resilience. Archives of Psychiatric Nursing, 27(6), 264-270. https://doi.org/l0.1016/j.apnu.2013.07.003

Gillespie, B., Chaboyer, W., \& Wallis, M. (2007). Development of a theoretically derived model of resilience through concept analysis. Contemporary Nurse, 25(I), 124-135. https://doi.org//0.5172/conu.2007.25.1-2.124

Glass, N., \& Rose, J. (2008). Enhancing emotional well-being through self-care. Holistic Nursing Practice, 22(6), 336-347. https:// doi.org/I0.1097/0I.hnp.0000339345.26500.62

Grafton, E., Gillespie, B., \& Henderson, S. (2010). Resilience: The power within. Oncology Nursing Forum, 37(6), 698-705. https:// doi.org/10.1188/10.onf.698-705

Hart, P., Brannan, J., \& De Chesnay, M. (2012). Resilience in nurses: An integrative review. Journal of Nursing Management, 22(6), 720-734. https://doi.org/10.1III/j.1365-2834.2012.01485.x

Kornhaber, R., \& Wilson, A. (20II). Building resilience in burns nurses: A descriptive phenomenological inquiry. Journal of Burn Care \& Research, 32(4), 48I-488. https://doi.org/10.1097/bcr.0b013e3182223c89

Lim, J., Bogossian, F., \& Ahern, K. (2010). Stress and coping in Australian nurses: A systematic review. International Nursing Review, 57(I), 22-31. https://doi.org/10.1III/j.1466-7657.2009.00765.x

Lowe, L. (2013). Creating a caring work environment and fostering nurse resilience. International Journal of Human Caring, I7(4), 52-59. https://doi.org/10.20467//091-57/0.17.4.52

McAllister, M., \& McKinnon, J. (2009). The importance of teaching and learning resilience in the health disciplines: A critical review of the literature. Nurse Education Today, 29(4), 371-379. https://doi.org/l0.1016/j.nedt.2008.10.01।

New Zealand Nurses Organisation. (2020). NZNO beyond 2020: A vision for nursing. Retrieved from https://www.nzno.org.nz/ LinkClick.aspx?fileticket=mfWDQ5fvK0I\%3D\&portalid=0

Rushton, C., Batcheller, J., Schroeder, K., \& Donohue, P. (20I5). Burnout and resilience among nurses practicing in high-intensity settings. American Journal of Critical Care, 24(5), 412-420. https://doi.org/I0.4037/ajcc201529I

Tabakakis, C., McAllister, M., Bradshaw, J., \& To, Quyen. (2019). Psychological resilience in New Zealand registered nurses: The role of workplace characteristics. Journal of Nursing Management, 27(7), I35 I- 1358. https://doi.org/l 0.1 I I I/jonm. I28 I5

Vahey, D., Aiken, L., Sloane, D., Clarke, S., \& Vargas, D. (2004). Nurse burnout and patient satisfaction. Medical Care, 42(2), $57-66$. https://doi.org//0.1097/0I.mlr.0000109126.50398.5a

Van Heugten, K. (2012). Resilience as an underexplored outcome of workplace bullying. Qualitative Health Research, 23(3), 29I301. https://doi.org/I0.1177//04973231246825।

World Health Organisation. (2006). The world health report 2006 - Working together for health. Retrieved from https://www.who. int/whr/2006/en/

Woods, M., Rodgers, V., Towers, A., \& La Grow, S. (2014). Researching moral distress among New Zealand nurses: A national survey. Nursing Ethics, 22(I), I17-130. https://doi.org/10.1177/0969733014542679

Yilmaz, E. (2017). Resilience as a strategy for struggling against challenges related to the nursing profession. Frontiers of Nursing, 4(I), 9-13. https://doi.org/l0.25164/cnr201701003 